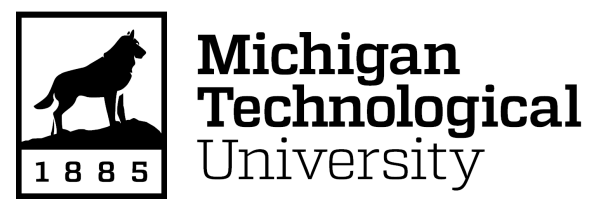

Michigan Technological University Digital Commons@ Michigan Tech

\title{
$9-2014$
}

\section{Modeling regional-scale wildland fire emissions with the wildland fire emissions information system}

\author{
Nancy H. F. French \\ Michigan Technological University \\ Donald McKenzie \\ Pacific Wildland Fire Sciences Laboratory \\ Tyler Erickson \\ Google \\ Benjamin Koziol \\ NESII, and CIRES, NOAA/ Earth System Research Laboratory \\ Michael Billmire \\ Michigan Technological University \\ See next page for additional authors \\ Follow this and additional works at: https://digitalcommons.mtu.edu/mtri_p \\ Part of the Environmental Sciences Commons, and the Forest Sciences Commons
}

\section{Recommended Citation}

French, N. H., McKenzie, D., Erickson, T., Koziol, B., Billmire, M., Endsley, K. A., Scheinerman, N. K., Jenkins, L. K., Miller, M. E., Ottmar, R., \& Prichard, S. (2014). Modeling regional-scale wildland fire emissions with the wildland fire emissions information system. Earth Interactions, 18(16). http://dx.doi.org/10.1175/ElD-14-0002.1

Retrieved from: https://digitalcommons.mtu.edu/mtri_p/14

Follow this and additional works at: https://digitalcommons.mtu.edu/mtri_p

Part of the Environmental Sciences Commons, and the Forest Sciences Commons 
Authors

Nancy H. F. French, Donald McKenzie, Tyler Erickson, Benjamin Koziol, Michael Billmire, K. A. Endsley, Naomi K. Yager Scheinerman, Liza K. Jenkins, Mary Ellen Miller, Roger Ottmar, and Susan Prichard 


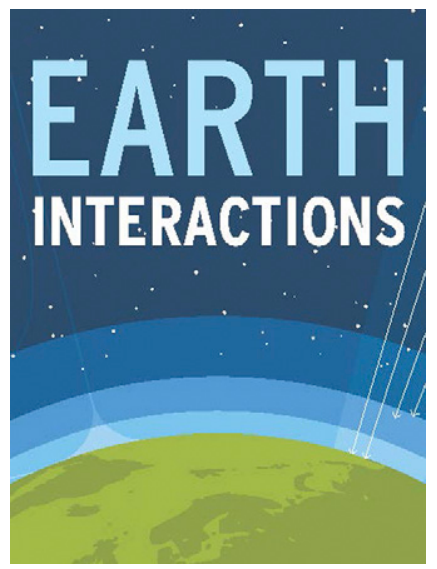

Copyright $\odot$ 2014, Paper 18-016; 73631 words, 7 Figures, 0 Animations, 4 Tables.

\section{Modeling Regional-Scale Wildland Fire Emissions with the Wildland Fire Emissions Information System*}

Nancy H. F. French, , , Donald McKenzie, ${ }^{\text {@ }}$ Tyler Erickson, ${ }^{+}$ Benjamin Koziol, ${ }^{* *}$ Michael Billmire, ${ }^{+}$K. Arthur Endsley, ${ }^{+}$ Naomi K. Yager Scheinerman, ${ }^{+}$Liza Jenkins, $^{+}$Mary Ellen Miller, ${ }^{+}$ Roger Ottmar, ${ }^{@}$ and Susan Prichard, ${ }^{++}$

${ }^{+}$Michigan Tech Research Institute, Michigan Technological University, Ann Arbor, Michigan

${ }^{\circledR}$ Pacific Wildland Fire Sciences Laboratory, U.S. Forest Service PNW Research Station, Seattle, Washington

\& Google, Moutainview, California

** NESII, and CIRES, NOAA/Earth System Research Laboratory, Boulder, Colorado

${ }^{++}$University of Washington, Seattle, Washington

Received 10 January 2014; accepted 15 May 2014

ABSTRACT: As carbon modeling tools become more comprehensive, spatial data are needed to improve quantitative maps of carbon emissions from fire. The Wildland Fire Emissions Information System (WFEIS) provides mapped

* Supplemental information related to this paper is available at the Journals Online website: http://dx.doi.org/10.1175/EI-D-14-0002.s1.

${ }^{\text {\# } C o r r e s p o n d i n g ~ a u t h o r ~ a d d r e s s: ~ N a n c y ~ H . ~ F . ~ F r e n c h, ~ M i c h i g a n ~ T e c h n o l o g i c a l ~ U n i v e r s i t y, ~}$ Michigan Tech Research Institute, 3600 Green Ct., Suite 100, Ann Arbor, MI 48105.

E-mail address: nhfrench@mtu.edu; dmck@u.washington.edu; tylerickson@gmail.com; ben.koziol@noaa.gov; mgbillmi@mtu.edu; kaendsle@mtu.edu; naomi.k.scheinerman@gmail. com; 1liverse@mtu.edu; marymill@mtu.edu; rottmar@fs.fed.us; sprich@u.washington.edu 
Earth Interactions - Volume 18 (2014) • Paper No. 16 • Page 2

estimates of carbon emissions from historical forest fires in the United States through a web browser. WFEIS improves access to data and provides a consistent approach to estimating emissions at landscape, regional, and continental scales. The system taps into data and tools developed by the U.S. Forest Service to describe fuels, fuel loadings, and fuel consumption and merges information from the U.S. Geological Survey (USGS) and National Aeronautics and Space Administration on fire location and timing. Currently, WFEIS provides web access to Moderate Resolution Imaging Spectroradiometer (MODIS) burned area for North America and U.S. fire-perimeter maps from the Monitoring Trends in Burn Severity products from the USGS, overlays them on 1-km fuel maps for the United States, and calculates fuel consumption and emissions with an open-source version of the Consume model. Mapped fuel moisture is derived from daily meteorological data from remote automated weather stations. In addition to tabular output results, WFEIS produces multiple vector and raster formats. This paper provides an overview of the WFEIS system, including the web-based system functionality and datasets used for emissions estimates. WFEIS operates on the web and is built using open-source software components that work with open international standards such as keyhole markup language (KML). Examples of emissions outputs from WFEIS are presented showing that the system provides results that vary widely across the many ecosystems of North America and are consistent with previous emissions modeling estimates and products.

KEYWORDS: North America; Geographic information systems (GIS); Biosphere-atmosphere interaction; Forest fires

\section{Introduction}

Early assessments of emissions from biomass burning were based on extrapolation from limited information on the extent of fire activity (Crutzen and Andreae 1990; Hao and Liu 1994; Pouliot et al. 2008; Seiler and Crutzen 1980). Global and regional assessments relied on fire-activity reports from land managers and government entities, quantifying burned area based on limited data. In some cases these assessments extrapolated from areas with rich information on fire activity to areas for which no data were available. Assumptions regarding the type of vegetation burned and characteristics of burning (e.g., combustion type and completeness) were broad because of the lack of resources required to properly attribute fire occurrences to land-use and land-cover type. More recent assessments are greatly improved with respect to quantifying fire occurrence, location, and site conditions during fires and in estimating quantities with geospatial tools such as remote sensing and geographic information systems (GIS).

In the last decade, global satellite inventories of fire activity have grown, based on 1) active fire detections from systems deploying thermal sensors such as the Advanced Very High Resolution Radiometer (AVHRR), Along Track Scanning Radiometer (ATSR), Tropical Rainfall Measuring Mission (TRMM) Visible and Infrared Scanner (VIRS), and Moderate Resolution Imaging Spectroradiometer (MODIS; e.g., Giglio et al. 2003, 2006; Le Page et al. 2008; Schultz 2002); 2) postfire mapping of burn scars with multispectral sensors for projects and systems such as GLOBCARBON (http://dup.esrin.esa.it/projects/summaryp43.asp), L3JRC (Tansey et al. 2008), and the MODIS MCD45A1 products (Roy et al. 2008); or 3) a combination of active-fire and burn-scar mapping such as in the Global Fire Emissions Database 
(GFED; Giglio et al. 2010) and Wildland Fire Emissions Inventory (WFEI; Urbanski et al. 2011). Finer-scale satellite mapping has also improved for some regions of Earth. In the United States, the Monitoring Trends in Burn Severity project (http:// mtbs.gov) has used 30-m-resolution Landsat imagery to map known fires back to 1982 (Eidenshink et al. 2007), and Canada has developed similar databases based on a combination of satellite and land-management records (Kasischke et al. 2011; Stocks et al. 2002). Despite relatively coarse resolution, the 500-1000-m datasets used in global assessment provide high temporal (1-3 days) and broad spatial coverage. Burned area mapping with these low-resolution remote sensing systems limits detection of small fires (less than 100 ha in size) typical of many small wildfires and controlled burns. The finer-resolution systems $(10-60 \mathrm{~m})$ can provide more spatially accurate fire size and location but are not globally comprehensive; they are limited in their coverage because of longer repeat cycles, therefore missing the onset of many fires and fires of short duration.

Global-scale fire emissions assessments, by necessity, use generalized or surrogate information to produce emissions estimates. For example, the GFED approach (van der Werf et al. 2010) uses modeled values for the amount of biomass (fuel loading). Some models partition burning by general vegetation type and vegetation strata (e.g., Hoelzemann et al. 2004; Wiedinmyer et al. 2011), which is a marked improvement over the early assessments that relied on one value for biomass and fuel consumption across vast regions. On the other hand, global models often do not separate different types of open burning. The satellite data products used to estimate fire activity do not explicitly separate wildfire from agricultural burning and other land-use activities such as deforestation, so an external source of information must be supplied to distinguish them. Furthermore, many models cannot account for the severity of a burn when assigning consumption level, which can lead to large uncertainty in emissions estimates. Agricultural fires, being generally smaller and of shorter duration than wildfires, pose specific problems for satellite-based detection (Hawbaker et al. 2008; McCarty et al. 2007) and are often undercounted in global remote sensingbased emissions assessments.

Kasischke and Penner (2004) evaluated the state of broad-scale emissions modeling in 2002 and concluded that the major sources of uncertainties differed by region. The accuracy of available global datasets is a factor limiting the accuracy of emissions estimates at global scales. For instance, based on land-cover validation data for the principal global products available at this time, such as Global Land Cover Characteristics (GLCC; Scepan 1999), Global Land Cover 2000 (GLC2000; Mayaux et al. 2006), and MODIS land-cover products (Friedl et al. 2002), the accuracy for separation of forest and nonforest cover types at a scale of $1 \mathrm{~km}$ is at best $90 \%$. Considering that fuel loadings in forests may be more than an order of magnitude greater than nonforest cover types (e.g., Guild et al. 1998), this translates into a substantial uncertainty for a model that assigns fuel properties based on general land-cover type, as many models do (Hyer and Reid 2009). The uncertainties in emissions from global-scale models are also driven by the accuracy of the burned area estimates they use. Giglio et al. (2010) found that the L3JRC and GLOBCARBON burned area products accounted for substantially more burned area in North America than reported by fire-management agencies, while GFEDv3 burned area data and MODIS MCD45A1 had slightly less burned area. 
Earth Interactions - Volume 18 (2014) • Paper No. 16 • Page 4

At finer scales and for emissions modeling over local or regional domains, the estimation methods used for wildland fire emissions can be based on in situ measurements of changes in ecosystem carbon stocks. Emissions are estimated by carbon pool and burn severity, which can then be spatially scaled using remote sensing information on burned area by fuel type and severity (Campbell et al. 2007; Michalek et al. 2000). These data are used in process models for estimating regional emissions (Hayes et al. 2011; Law et al. 2004) and are the basis for fire emissions models developed by the U.S. Forest Service (Prichard et al. 2009; Reinhardt et al. 1997) and the Canadian Forest Service (de Groot et al. 2009) that have been used in regional emissions tools and inventories (Larkin et al. 2009; Urbanski et al. 2011). They are also used by the U.S. Environmental Protection Agency (USEPA) and other government agencies to assess biomass burning for emission inventories and air quality assessments (Raffuse et al. 2012).

In this paper we describe a recently developed system for modeling regionalscale forest fire emissions within the United States called the Wildland Fire Emissions Information System (WFEIS). ${ }^{1}$ The system builds from earlier work on fire emissions modeling and uses tools developed for both global fire mapping and land and fire management to make spatial estimates of fire-derived carbon and trace gas emissions. WFEIS is both a modeling method and a web-based system to employ the method that can be used to calculate past fire emissions for userdesignated time and space domains. WFEIS provides a means to map and quantify emissions across multiple fires revealing within-burn variability based on fuels and fire timing. Currently, WFEIS is operational for the contiguous United States (CONUS) and Alaska (AK) for areas of forest and rangeland and is not able to account for burning in croplands. Daily estimates are derived and are reported by fuel type. Unlike other emissions modeling activities [e.g., WFEI, GFED, and Fire Inventory from the National Center for Atmospheric Research (FINN); Urbanski et al. 2011; van der Werf et al. 2010; Wiedinmyer et al. 2011], WFEIS is not an inventory of fire emissions but rather a system that provides open access to the modeling tools needed to quantify emissions from past fires. Emissions data at these spatial and temporal scales are valuable for providing detailed information for a variety of disciplines including fire science, smoke management, emissions inventories, and carbon cycle science. The paper presents a review of the system and development activities followed by demonstration of some of the outputs possible from the web-based user interface.

\section{Development and structure of WFEIS}

The WFEIS (http://wfeis.mtri.org/) is a web-based tool that provides a userfriendly interface for computing wildland fire emissions at regional scales $(1-\mathrm{km}$

\footnotetext{
${ }^{1}$ The version of WFEIS available at the time of the writing of this overview is version 0.3 . Some system modifications are in progress including the addition of cropland fuels, so future versions will include features not reviewed here. These new features could change the outputs reported but are not expected to include any changes that would substantially alter the results or conclusions presented in this paper aside from outputs for regions dominated by croplands. See the website (http:// wfeis.mtri.org) for information on recent upgrades and changes and to compute the most up to date estimates of emissions.
} 
Earth Interactions - Volume 18 (2014) • Paper No. 16 • Page 5

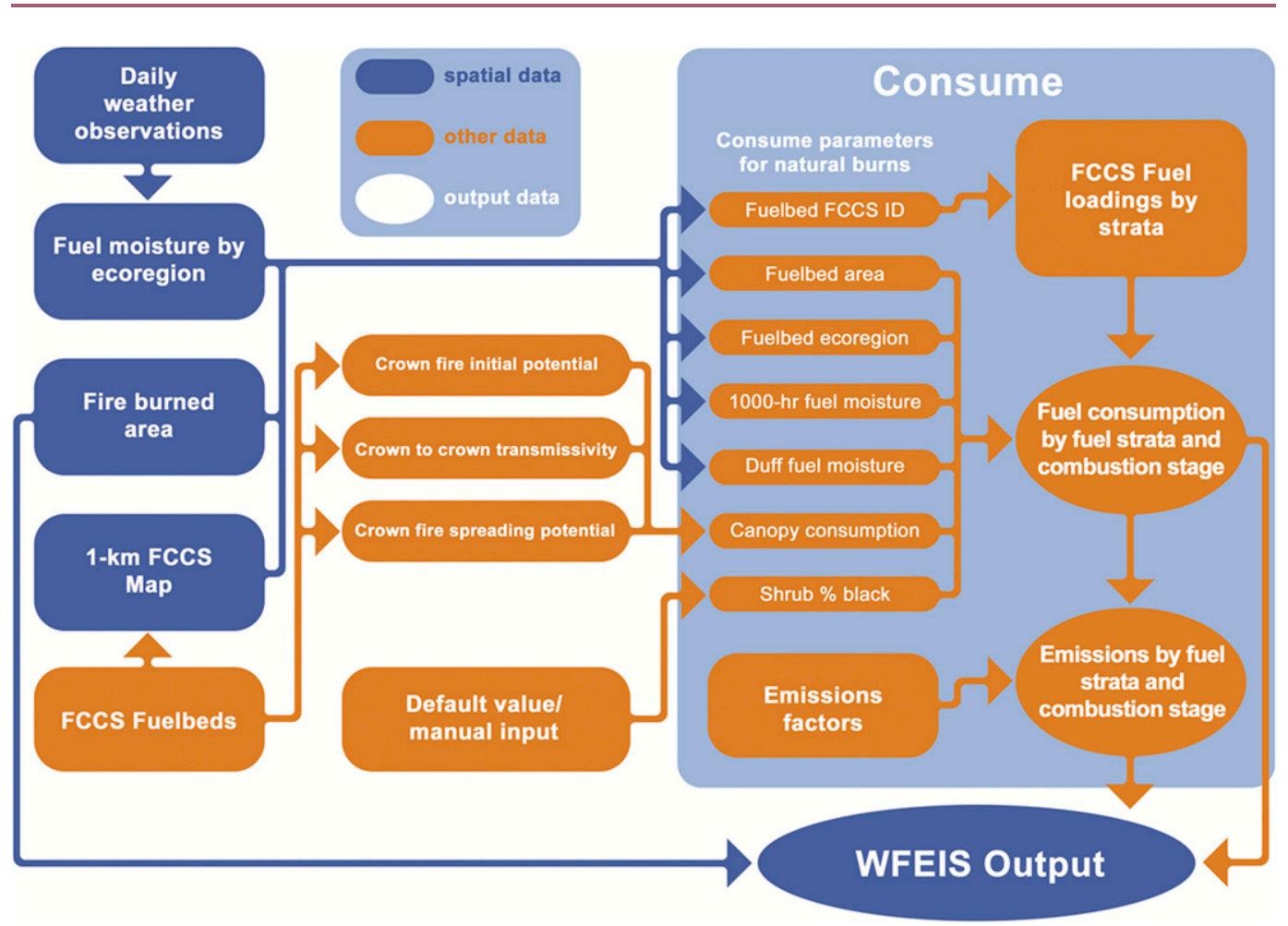

Figure 1. Simplified schematic of the Consume model as used within WFEIS.

spatial resolution). Estimates of carbon emissions are made using an existing emissions model (Consume; Prichard et al. 2009) that works in conjunction with mapped fuels from the Fuel Characteristic Classification System (FCCS; Ottmar et al. 2007) and other geospatial datasets that were developed for the system (Figure 1). Although total carbon emission has been the main focus for development, the Consume model allows for estimation of many smoke constituents, including criteria air pollutants defined by the USEPA. WFEIS is currently operational for the CONUS and AK with fire occurrence data from 1984 to 2011. The web system provides access to fire-perimeter maps along with corresponding fuel loadings and models to compute fuel consumption and fire emissions for userspecified locations and date ranges. The FCCS fuels map does not cover croplands, so fire emissions mapping within WFEIS is limited to noncropland land types. This will be addressed in future versions.

Many data inputs required for emissions modeling are calculated within the system using site-specific environmental data based on the user's spatial selection, eliminating the need for operator input (Table 1). Some data layers are precalculated using spatial data analysis, including fire progression and fire weather to compute fuel moisture. The WFEIS system operates entirely online and is built using open-source software that works with international standards such as keyhole markup language (KML), which allows for the display of outputs on a virtual globe such as Google Earth. 
Earth Interactions - Volume 18 (2014) • Paper No. 16 • Page 6

Table 1. Summary of input variables for Consume emissions models as implemented within WFEIS.

\begin{tabular}{|c|c|c|c|}
\hline $\begin{array}{l}\text { Consume } \\
\text { variable }\end{array}$ & Units & Description & $\begin{array}{l}\text { WFEIS implementation } \\
\text { (see text for details) }\end{array}$ \\
\hline $\begin{array}{l}\text { 1000-h fuel } \\
\text { moisture }\end{array}$ & Index value & $\begin{array}{l}\text { Moisture status of the dead plant } \\
\text { material with a diameter of } 7.6- \\
20 \mathrm{~cm} \text {, the largest fuel category in } \\
\text { the NFDRS with the longest lag } \\
\text { time (Deeming et al. 1978) }\end{array}$ & $\begin{array}{l}\text { Computed daily from station } \\
\text { weather-based calculations } \\
\text { extrapolated to ecoregion }\end{array}$ \\
\hline $\begin{array}{l}\text { Duff fuel } \\
\text { moisture }\end{array}$ & Percent & $\begin{array}{l}\text { Moisture in loosely compacted duff } \\
\text { layers on the forest floor }\end{array}$ & $\begin{array}{l}\text { Computed daily from gridded } \\
\text { weather data extrapolated to } \\
\text { ecoregion }\end{array}$ \\
\hline $\begin{array}{l}\text { Canopy } \\
\text { consumption }\end{array}$ & Percent & $\begin{array}{l}\text { The amount of tree canopy fuel } \\
\text { consumed in the fire }\end{array}$ & $\begin{array}{l}\text { Based on crown fire potential of fue } \\
\text { bed at site of the fire }\end{array}$ \\
\hline $\begin{array}{l}\text { Shrub } \\
\quad \text { blackened }\end{array}$ & Percent & $\begin{array}{l}\text { The amount of area with shrubs } \\
\text { impacted by the fire (blackened) }\end{array}$ & $\begin{array}{l}\text { Default set to } 50 \% \text {; user permitted to } \\
\text { modify across full extent of } \\
\text { model run }\end{array}$ \\
\hline
\end{tabular}

\subsection{Fire extent and timing}

Fire occurrence data are available from a variety of sources (Kasischke et al. 2011). WFEIS uses satellite-derived polygons of burned area. As it operates currently, three wildland fire burned area products are available within WFEIS to define the spatial and temporal extent of fires: 1) the Landsat-based Monitoring Trends in Burn Severity (MTBS) perimeter product, which is available for 19842011; 2) the MODIS-derived MCD64A1 500-m burned area product for 2001-10; and 3) a hybrid Landsat/MODIS active fire (MCD14ML) product that was created for use in WFEIS covering CONUS and AK.

For all three burn-area products, WFEIS accesses the day of burning for a fire or spatial unit within a fire to assign fuel moisture, which is one of the key variables that determines consumption within the Consume model. Day of burning is relevant for emissions mapping due to varying fuel conditions driven by weather (see below). The first of these products (Landsat MTBS perimeter) provides just one date for the entire perimeter, drawn from the start date of the fire contained in the MTBS database record. The other two products provide a more refined estimate of the day of burning based on the fact that MODIS samples the globe at least twice daily. The two daily resolved products allow daily emissions to be computed and reported by WFEIS. The MODIS MCD64A1 product estimates the day of burning for each 500-m grid cell and is accurate within 8 days, although it is often better than 8 days (see Giglio et al. 2010). The third choice (Landsat/MODIS Active Fire product) similarly assigns a date to each grid cell through an interpolation algorithm based on MODIS-detected fire hot spots within the Landsat perimeter.

The MTBS products [available from the U.S. Geological Survey (USGS) at http://www.mtbs.gov/] were developed to exploit the extensive Landsat image archive to map perimeters of known fires and the variability of burn severity detected by the sensor. MTBS products are derived from Landsat data with a spatial resolution of $30 \mathrm{~m}$ and created for known fires greater than 200 ha in size for the eastern United States and 400 ha for the western United States, where forest fires are generally larger. The methods for perimeter and severity mapping are based on 
Earth Interactions - Volume 18 (2014) • Paper No. 16 • Page 7

the pre- and post-burn differences in spectral ratios of the near- and mid-infrared spectral bands [Landsat Thematic Mapper (TM)/Enhanced Thematic Mapper Plus (ETM+) bands 4 and 7; Eidenshink et al. 2007; Key and Benson 2005]. While the severity products produced for the MTBS program have value for understanding variability in fuel consumption for some sites, that information is not exploited by WFEIS because of the complexity of translating MTBS-mapped severity into fuel consumption (French et al. 2008). For emissions calculation, WFEIS uses the MTBS burn perimeters and does not use the severity data. The utility of the severity mapping methods as well as the perimeter maps has been extensively reviewed in the literature (e.g., French et al. 2008; a list of publications using the MTBS methods can be found at http://www.mtbs.gov/scientificreferences.html).

At 500-m grid scale, the spatial resolution of the MODIS burned area product (MCD64a1) is coarser than Landsat-based products, but it provides a finer temporal resolution because of the twice-daily overpass schedule of the MODIS sensors (see http://modis.gsfc.nasa.gov/about/). MODIS MCD64A1 is derived from MODIS daily surface reflectance products (MOD/MYD09GHK), daily active fire products (MOD/MYD14A1), and the 96-day land-cover product (MOD12Q1) to create a 500-m spatial-resolution burn probability product that resolves fire timing within one day (Giglio et al. 2010). Formerly known as the Direct Broadcast Burned Area Product (DBBAP), MCD64A1 was initially developed and downscaled in spatial resolution for use in the GFED modeling activity (van der Werf et al. 2006) and serves as the main dataset for post-2000 burned area for GFED versions 2, 3, and 4.

The third choice for burned area combines the spatial resolution and capabilities of Landsat used in the MTBS product with the daily temporal resolution of MODIS by exploiting the MODIS thermal channel to detect active fire (Giglio et al. 2006). This product was created for use within WFEIS using an inverse distance-weighted interpolation of the MODIS active fire detections (MCD14ML) based on the fire spread reconstruction algorithm described by Loboda and Csiszar (2007). The result is daily modeled fire progression within each MTBS fire perimeter at a 200-m grid-scale resolution.

\subsection{Vegetation fuels map}

Information on the live and dead vegetation biomass that serves as fuel for wildland fire is required to properly calculate fire emissions (Ottmar et al. 2009; Ottmar 2014). The WFEIS uses the FCCS for the fuel descriptions and loadings required by the emissions model (Ottmar et al. 2007; Riccardi et al. 2007b). The FCCS provides a conceptual framework for describing fuel beds based on the composition and structure of wildland fuels found in specific forest and rangeland sites (Riccardi et al. 2007a). Fuel beds are represented by six horizontal fuel strata: canopy, shrubs, herbs, downed wood, a litter-lichen-moss layer, and ground fuels (e.g., organic soil or duff). Strata are further divided into categories and subcategories. The FCCS structure represents the inherent variability of wildland fuel beds for fire behavior and effects modeling (e.g., the amount of fuel consumed during a fire, the amount of remaining material by fuel stratum, and the amount and composition of the smoke derived from the fire). The FCCS calculates fuel load by fuel stratum and category and provides some fire-behavior characteristics, such as 
Earth Interactions • Volume 18 (2014) • Paper No. 16 • Page 8

predicted surface fire behavior (e.g., flame length and rate of spread and an index of crown fire potential (e.g., crown fire initiation and spread), which are driven by the fuel bed type and structure (Prichard et al. 2013). WFEIS uses FCCS-derived fuel loads by strata and crown fire potential in computing fire emissions.

FCCS fuel beds, representing fuels as diverse as subtropical forests to tundra sedge, are mapped for CONUS and AK (McKenzie et al. 2012), providing spatially delineated fuel bed classes at 1-km resolution. This data layer is an aggregation of the 30-m product produced by the Landscape Fire and Resource Management Planning Tools (LANDFIRE; http://www.landfire.gov/) project using the existing vegetation map and then aggregated to 1-km cells based on majority type (French et al. 2014).

\subsection{The Consume emissions model}

To estimate fuel consumption and calculate emissions WFEIS uses the United States Department of Agriculture (USDA) Forest Service Consume model (Prichard et al. 2009). Consume uses empirically derived equations that relate fuel loadings and fuel moisture parameters to fuel consumption for each fuel stratum (Ottmar 2014). Based on consumption estimates, the software uses hard-coded emission factors compiled by the USFS to calculate emission of carbon dioxide $\left(\mathrm{CO}_{2}\right)$, carbon monoxide $(\mathrm{CO})$, methane $\left(\mathrm{CH}_{4}\right)$, particulates $\left(\mathrm{PM}_{2.5}\right.$ and $\left.\mathrm{PM}_{10}\right)$, and nonmethane hydrocarbons (NMHC) by fuel stratum and combustion stage (flaming, smoldering, and residual burning; emission factors used within Consume are available from the WFEIS webpage: http://wfeis.mtri.org/media/img/A3-EmissionFactors.pdf). Because consumption during flaming is more efficient than during smoldering combustion and different emission factors are applied depending on the chemical compound of interest, separate calculations of flaming consumption and smoldering consumption are applied for the assessment of greenhouse gas and aerosol emissions. Consume connects directly to the FCCS by accepting FCCS-derived fuel loadings as inputs for the consumption and emissions calculations. Within WFEIS, fuel loadings for each fuel-bed stratum are accessed by Consume by overlaying the burned area of a fire on the FCCS fuel-bed map. For fires $>1 \mathrm{~km}^{2}$, within-fire fuels will vary spatially based on the FCCS fuel-bed map.

As developed by the USFS, the Consume model requires operator input; it assumes that the operator has some basic knowledge of the fire location and type (e.g., prescribed versus wildfire). Within WFEIS, however, Consume employs default inputs derived from weather data and FCCS fuel-bed information, requiring no operator input beyond choosing the region and timeframe of interest. The sources of the inputs to Consume that are used within WFEIS are the U.S. National Fire Danger Rating System (NFDRS) 1000-h time-lag fuel moisture (FM); duff fuel moisture; percent canopy consumption; and shrub blackened, a variable used to define the extent of the shrub component affected by fire (Table 1). An updated version of Consume (version 4.1) written in Python is used within WFEIS; it is the same version of Consume code used within other USFS tools.

\subsubsection{NFDRS 1000-h fuel moisture}

The NFDRS is used within the United States to measure and predict fire potential and fire danger on a national scale. One variable tracked by the NFDRS for estimating 
fire danger is fuel moisture content for the large dead woody debris of $7.6-20.0 \mathrm{~cm}$ in diameter (i.e., 1000-h fuels). This variable is one of the critical parameters for estimating fuel consumption by Consume (Ottmar 2014). These are the largest fuels tracked in the NFDRS; they have a small surface area compared to volume and respond slowly to changes in atmospheric moisture (Deeming et al. 1978).

Daily NFDRS 1000-h FM values are estimated empirically from weather data for the previous 7 days and the initial 1000-h fuel moisture content (Ottmar and Sandberg 1985). The empirical estimate uses daily minimum and maximum temperature; daily minimum and maximum relative humidity; the duration of any precipitation events; and solar insolation, which is estimated using station latitude. Weather data for the NFDRS are collected for over 2000 remote automatic weather system (RAWS) fire weather stations located across the United States and available from the USFS (http://raws.fam.nwcg.gov/). Depending on location, stations gather data either continuously or only during the fire season. Occasionally, stations are missing observations, but in some cases the missing data are estimated and available from the USFS database. Portable stations are also temporarily deployed in order to monitor conditions near large fires.

Calculated fuel moistures are not archived by the USFS, so the NFDRS 1000-h FM estimates used in WFEIS were recalculated in order to obtain historical fuel moisture maps. The archived RAWS weather station data were downloaded from the National Fire and Aviation Management Fire and Weather data site (http://fam.nwcg.gov/famweb/weatherfirecd/index.htm). Historical NFDRS 1000-h FM was determined using equations found in Cohen and Deeming (1985) and from code used in Fire Family Plus (L. Bradshaw, USDA Forest Service, 2011, personal communication). Values were generated using the same algorithms used by the Forest Service and therefore are subject to the same weaknesses. For instance, stations that gather data seasonally may not have useful early season data because the computation requires an estimation of the initial 1000-h FM, which needs roughly a month of initial daily measurements. Fuel moistures for all stations with data after 1982 were used for determining daily fuel moisture on an ecoregion scale. Currently, the WFEIS database of NFDRS 1000$\mathrm{h}$ fuel moistures contains 2138 stations with over 8 million daily records.

To determine fuel moisture at a site during the burn, WFEIS currently uses daily maps of 1000-h FM, which have been precalculated for each day of the fire record for each ecoregion of CONUS and AK (Baileys level II; http://www.nationalatlas. gov/mld/ecoregp.html). Interpolation to ecoregion level from station data used block kriging to generate best estimates of fuel moisture. Block kriging is a geostatistical technique used in cases where an area estimate for a region is preferred over the more common point-based interpolation (Goovaerts 1997). In this case the blocks are equivalent to polygon representations of ecoregion boundaries. They are first delineated and then a discretization grid is chosen. The grid is a tessellation of regularly spaced points at which the response variable (fuel moisture) is estimated and then summarized over the block. A 100-km grid spacing was used in WFEIS, which ideally captures the spatial variability of landscape fuel moisture while also minimizing the computations required for geostatistical estimation. While extrapolation across a large ecoregion is not optimal and introduces errors based on assumptions that stations represent large regions, the decision to create spatially general and temporally finescale representations of fuel moisture was made to reduce computational burden for the spatial emissions modeling. Future versions of 
Earth Interactions - Volume 18 (2014) • Paper No. 16 • Page 10

WFEIS will include more elegant ways of representing fuel moisture (e.g., gridded fuel moisture) as computation limitations are resolved.

\subsubsection{Duff fuel moisture}

Duff FM as a percentage of dry weight is a second fuel moisture variable used in calculating fuel consumption within Consume in some fuel strata. As with the 1000-h FM variable, duff FM is determined using weather data and is included within WFEIS as a spatial data layer that changes daily and is spatially aggregated to the ecoregion level. In the WFEIS system, duff FM is determined by calculating the duff moisture code (DMC) of the Canadian Fire Weather Index (FWI) system. The FWI DMC is a numerical rating of the fuel moisture in shallow to medium loosely compacted duff at a depth of 10-20 cm and in medium-weight surface fuels (Van Wagner 1987). FWI DMC is then converted to percent duff FM according to the following equations separately for CONUS and AK from Lawson et al. (1997):

duff FM (\%) for CONUS,

$$
\% \text { duff } \mathrm{FM}=e^{[(\mathrm{DMC}-244.7) /-43.4]+20}, \quad \text { and }
$$

duff FM (\%) for Alaska,

$$
\% \text { duff } \mathrm{FM}=e^{[(\mathrm{DMC}-149.6) /-20.9]} .
$$

In version 0.3 of WFEIS, the FWI DMC is derived from the North American Regional Reanalysis (NARR; http://www.emc.ncep.noaa.gov/mmb/rreanl/) weather data, a gridded dataset facilitating calculation across the CONUS and AK. DMC was calculated using the Canadian FWI system from specific measured parameters: temperature, relative humidity, rain, and wind speed, as well as the previous day's DMC, month the measurement was made, and latitude. A spring initiation DMC value is necessary to compute subsequent days' DMC values. Since the start day each year is difficult to define systematically, the FWI was run continuously starting in mid-1999; for this reason, a gridded base dataset was preferred. An analysis was conducted to determine if this approach was appropriate to ensure that the equations were stable over long periods of time. As with 1000-h fuel moisture, daily estimates of duff moisture were calculated and aggregated to the ecoregion level using block kriging (Bailey's level II; Bailey and Hogg 1986). In the future, daily gridded duff FM and 1000-h FM will be calculated and used within WFEIS.

\subsubsection{Shrub and canopy consumption in WFEIS}

WFEIS uses the crown fire potential defined for each FCCS fuel bed to determine percentage of canopy consumption as an input to Consume. Each FCCS fuel bed contains information to calculate the crown fire potential, which is the weighted average of three crown fire subpotentials: 1) crown fire initiation potential (CFIP), the potential for fire to reach canopy layer; 2) crown-tocrown transmissivity (C2CT), the potential for fire to carry through the canopy; and 3) crown fire spreading potential (CFSP), a relative index of crown fire rate of 


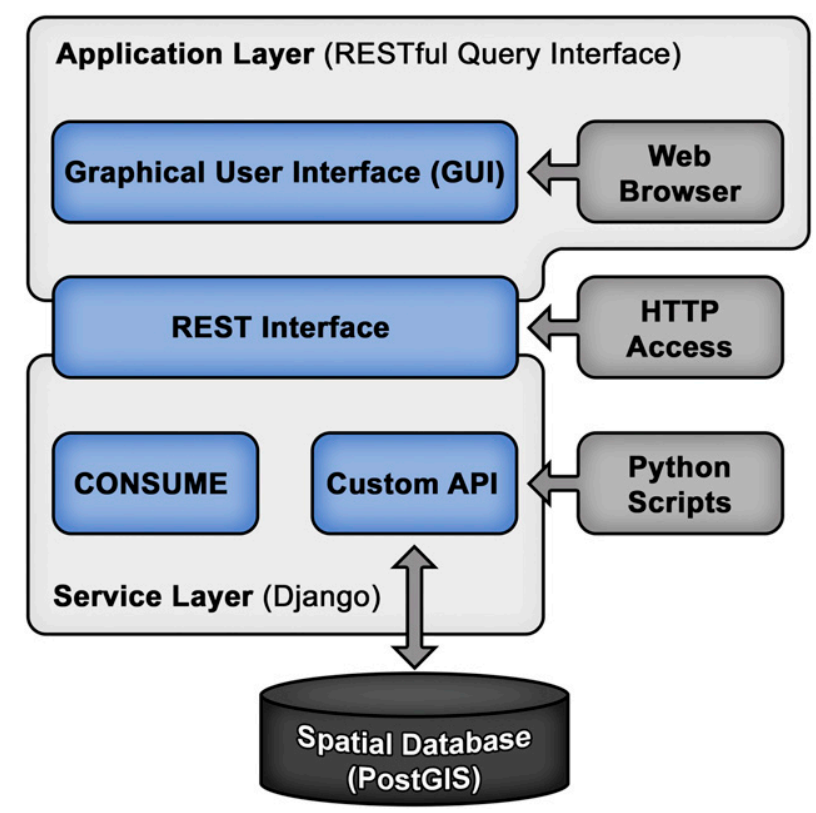

Figure 2. Overview of the WFEIS API and database structure.

spread. WFEIS uses an integrated assessment of the subpotentials to calculate the percentage canopy consumption as follows:

- If the CFIP is low (less than or equal to 3), then canopy consumption is zero.

- If the CFIP is greater than 3, then canopy consumption is calculated as a function of the other two subpotentials using the following relationship:

$$
\text { Canopy consumption } \%=[(\mathrm{C} 2 \mathrm{CT} \times 0.5)+(\mathrm{CFSP} \times 0.5)] \times 10 \text {. }
$$

As with canopy consumption, shrub blackened (SB) is one of the inputs required in Consume that was originally specified by the user. SB is a description of the percentage of the shrub cover in the area burned impacted by the fire. The variable is required only in fuel beds that have a shrub component. For the WFEIS implementation of Consume, SB is set to a default of 50\%. With little research on the drivers of the variable, we decided to leave the input constant in our initial WFEIS version. Users are able to modify this input, but the default is $50 \%$.

\subsection{WFEIS framework and operation}

WFEIS has been developed as a web-enabled tool for emissions estimation with the philosophy of free access to data for the benefit of any user. With this in mind, WFEIS is built entirely from open-source software components, facilitating development of the web-accessible data and modeling framework by anyone who would like to customize the system. There are two main components: the WFEIS front-end emissions calculator graphical user interface (GUI) and the WFEIS server software ("back end"), where the database resides and emissions calculations are performed (Figure 2). 
Earth Interactions - Volume 18 (2014) • Paper No. 16 • Page 12

There are two approaches available for making fuel consumption and emissions estimates using WFEIS. First, WFEIS responds to queries submitted via properly encoded requests from a web browser. Specifically, WFEIS uses a representational state transfer (REST) software architecture to implement a web-based application programming interface (API) through which requests for emissions modeling calculations are made. Each request is encoded as a uniform resource identifier (URI), a hyperlink effectively representing the result of an emissions query on the web. Second, there is the web-based emissions calculator, a GUI that guides users in the construction of proper queries (proper URIs). Most users will be more comfortable with the emissions calculator as it provides guidance on input selections and query requirements. Advanced users can bypass the emissions calculator and submit requests for emissions queries directly through the REST API.

The emissions calculator (Movie 1) allows users to interactively build the URI required to access the REST API. Through this interface, users choose the burn area product they prefer, the time frame of the desired calculation, the spatial extent, and modifications to input variables along with output data formats and units. Users can select any one of several predefined spatial extents (state, ecoregion, an MTBS fire, or air quality partnership boundary) or define a rectangular bounding box in the map display. The query is submitted to the WFEIS server application, a Python web framework, in which the spatially explicit calculations are performed. Output files are then sent back to the users in the form of a file or ZIP archive depending on the output format chosen.

Output data from WFEIS can be requested as a plain-text report, Community Multiscale Air Quality (CMAQ)-compatible comma-delimited text format or in a variety of vector or raster spatial formats including Esri shapefile, Google KML, georeferencing TIFF (GeoTIFF), and netCDF. The URI created by the emissions calculator can be accessed from the designated output format chosen. This URI can be "bookmarked" or saved (like any hyperlink), shared with others, and any time later resubmitted through any web browser to repeat the query. WFEIS URIs can also be modified by hand, for example, changing the date range in an otherwise identical query. This feature is useful for making repeat requests with few or no changes or for building batch queries for aggregation of results.

\section{WFEIS outpults and results}

WFEIS was designed to help the emissions and smoke communities access reliable and consistent data on fire emissions through a simple-to-use web-based system. Open-source software tools were used to build the system, and the WFEIS website serves out base datasets and modeling code so that users can access the building blocks for calculating spatially explicit wildland fire emissions (Table 2). The value of WFEIS is twofold: 1) to allow a broad set of users easy access to information on the amount of carbon and other trace gas emissions at a given time frame and location and 2) to summarize results in output formats that can be used to analyze and visualize the impacts of wildland fire on air quality and the atmosphere. Here we show several examples of WFEIS outputs and review some results for assessing fire emissions from CONUS and AK.

In running WFEIS for the full area of CONUS and AK (Tables 3 and 4 and Movie 1), we see large variability in interannual and inter-ecoregion emissions 
Earth Interactions - Volume 18 (2014) - Paper No. 16 • Page 13

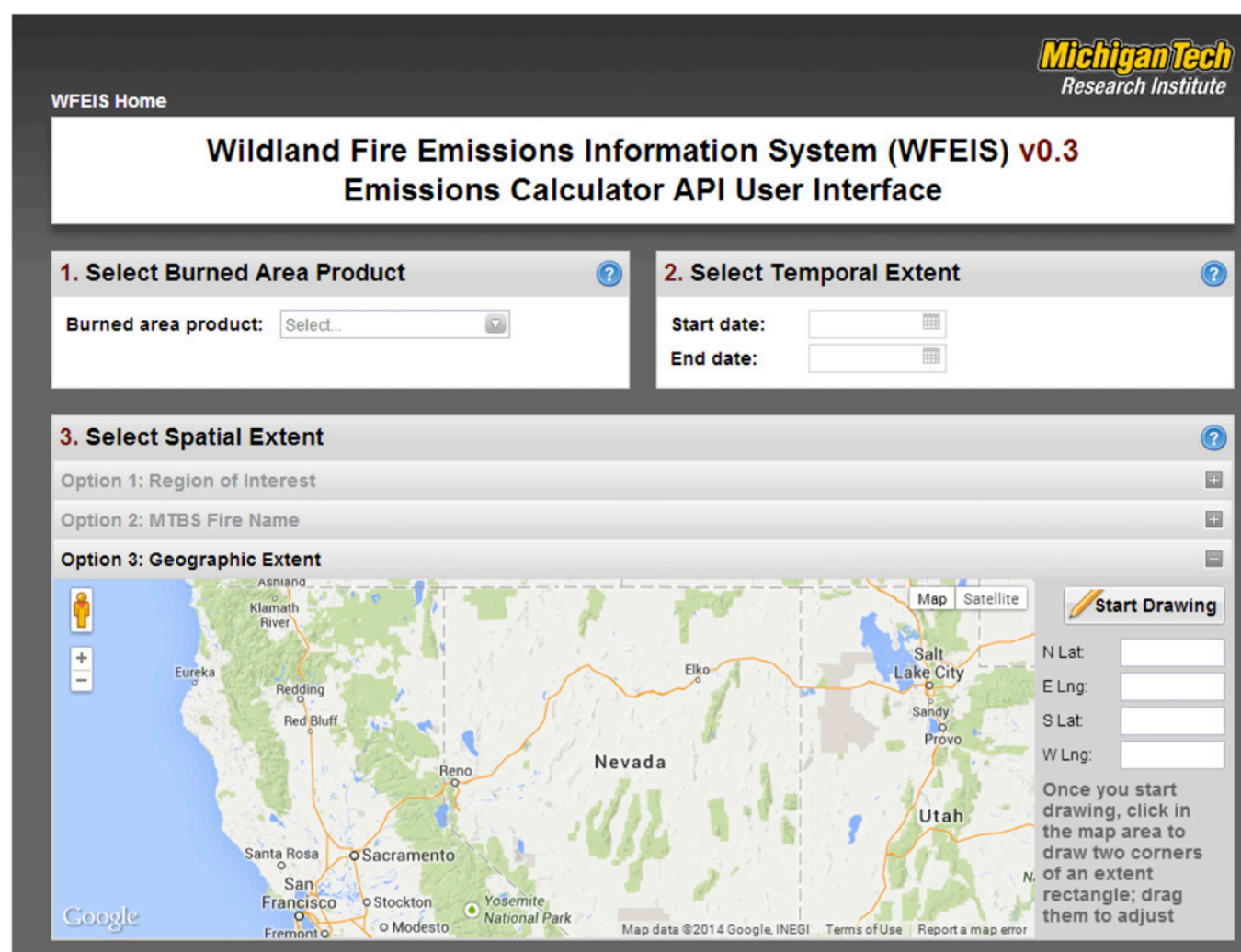

4. Optional Filters

By EPA Source Classification Code (SCC): All sources (Default)

5. Customize WFEIS Parameters (Advanced)

$\square$ Use default WFEIS parameters (recommended)

Moisture scenario:

1000-hour fuel moisture:

Duff fuel moisture (\%):

Shrub blackened $(\%)$ :

Combustion stage:

Stratum:
Canopy consumption (\%):

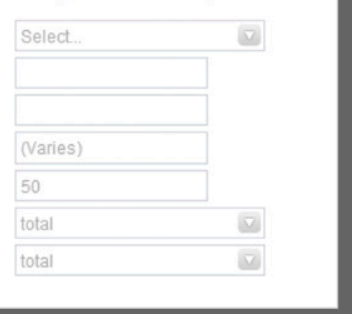

6. Select Output Formats

Units:

Output data type:

Fuel consumption

emission type:

Grid resolution

(degrees):

Reset Form

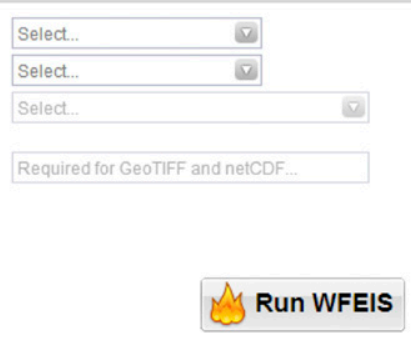

Movie 1. Webpage of the WFEIS v0.3 emissions calculator API user interface (http:// wfeis.mtri.org/calculator): Movie begins at the WFEIS homepage (http:// wfeis.mtri.org/). Clicking on the "emissions calculator" button leads to the calculator page, where various extents and options can be selected. The "run WFEIS" button generates data based on user selections, displaying the results in the chosen format in a new Internet browser tab. 
Earth Interactions V Volume 18 (2014) • Paper No. 16 • Page 14

Table 2. List of datasets and tools available from the WFEIS website (http://wfeis.mtri. org).

\begin{tabular}{|c|c|c|}
\hline Product & Web link for data access & Description \\
\hline MODIS burned area & $\begin{array}{l}\text { ftp://wfeis:fire@ @tp.mtri. } \\
\text { org/ }\end{array}$ & $\begin{array}{l}\text { Polygons of burned area derived from 500-m-scale } \\
\text { MODIS for 2001-11. This is the MCD64A1 } \\
\text { burned area product described in Giglio et al. } \\
\text { (2009). }\end{array}$ \\
\hline Landsat burned area & http://mtbs.gov/ & $\begin{array}{l}\text { Access to the USGS website that serves out Landsat } \\
\text { MTBS data; WFEIS uses the perimeters of these } \\
\text { fires; data are available for 1984-2010 (http:// } \\
\text { www.mtbs.gov/) }\end{array}$ \\
\hline FCCS fuels map & $\begin{array}{l}\text { http://wfeis.mtri.org/ } \\
\text { fuelsmap }\end{array}$ & $\begin{array}{l}\text { FCCS standard fuel beds used within WFEIS are } \\
\text { mapped at a 1-km grid-scale for CONUS and } \\
\text { Alaska from a 30-m grid-scale product } \\
\text { produced under the LANDFIRE project (http:// } \\
\text { www.landfire.gov/) }\end{array}$ \\
\hline $\begin{array}{l}\text { FCCS fuels code names } \\
\text { and descriptions }\end{array}$ & $\begin{array}{l}\text { http://wfeis.mtri.org/ } \\
\text { media/Docs/FCCS_ } \\
\text { fuelbed_IDs_and_- } \\
\text { descriptions.csv }\end{array}$ & $\begin{array}{l}\text { List of FCCS codes with descriptor names and de- } \\
\text { tailed description; more information, including } \\
\text { references to studies used to build these data at } \\
\text { http://www.fs.fed.us/pnw/fera/fccs/index.shtml }\end{array}$ \\
\hline Emissions factors & $\begin{array}{l}\text { http://wfeis.mtri.org/ } \\
\text { media/img/ } \\
\text { A3-EmissionFactors. } \\
\text { pdf }\end{array}$ & $\begin{array}{l}\text { List of emissions factors used within Consume for } \\
\text { calculating emissions species: these are published } \\
\text { and unpublished data as detailed in the document }\end{array}$ \\
\hline Consume model & $\begin{array}{l}\text { http://code.google.com/ } \\
\text { p/python-consume/ }\end{array}$ & $\begin{array}{l}\text { Python version of the Consume model created and } \\
\text { maintained in coordination with the USFS origi- } \\
\text { nators (Joint Fire Science Program 2009) }\end{array}$ \\
\hline $\begin{array}{l}\text { Canadian fire weather } \\
\text { index code }\end{array}$ & $\begin{array}{l}\text { http://code.google.com/ } \\
\text { p/pyfwi/ }\end{array}$ & $\begin{array}{l}\text { Python version of the Canadian FWI equations (Van } \\
\text { Wagner 1987) }\end{array}$ \\
\hline
\end{tabular}

across the United States. Table 3 shows 2003, which is a moderate year for burning in CONUS and a low year in AK but representative of the patterns seen from ecoregion to ecoregion. Figure 3 shows these outputs and demonstrates a set of information that can be derived from running WFEIS for many scenarios. In assessing interannual emissions, it is obvious that burned area is an important driver

Table 3. Compiled data from WFEIS v0.3 on burned area, consumption, and emissions for 2003 by level-1 ecoregion (Commission for Environmental Cooperation 1997).

\begin{tabular}{clcrr}
\hline Ecoregion No. & \multicolumn{1}{c}{ CONUS ecoregion } & $\begin{array}{c}\text { Burned } \\
\text { area }\left(\mathrm{km}^{2}\right)\end{array}$ & $\begin{array}{c}\text { Total fuel } \\
\text { consumption }(\mathrm{Tg})\end{array}$ & $\begin{array}{r}\text { Total } \\
\mathrm{CO}_{2}(\mathrm{Tg})\end{array}$ \\
\hline 3.0 & Alaska taiga & 2322 & 24.00 & 19.08 \\
9.0 & Great Plains & 5236 & 9.14 & 7.55 \\
6.0 & Northwestern forested mountains & 4086 & 30.83 & 24.81 \\
11.0 & Mediterranean California & 3123 & 7.81 & 11.31 \\
8.0 & Eastern temperate forests & 2736 & 3.28 & 2.72 \\
15.0 & Tropical wet forests & 1052 & 0.03 & 0.03 \\
10.0 & North American deserts & 965 & 0.42 & 0.51 \\
13.0 & Temperate Sierras & 723 & 1.62 & 1.45 \\
12.0 & Southern semiarid highlands & 380 & 0.57 & 0.49 \\
5.0 & Northern forests & 94 & 1.63 & 1.28 \\
7.0 & Marine West Coast forest & 56 & 0.29 & 0.23 \\
\hline
\end{tabular}


Earth Interactions - Volume 18 (2014) • Paper No. 16 • Page 15

Table 4. Annual burned area, consumption, and emissions results from WFEIS v0.3 for CONUS 2005 and AK 2007, for large fire years in each region.

\begin{tabular}{|c|c|c|c|c|c|c|}
\hline \multirow[b]{2}{*}{ Year } & \multicolumn{2}{|c|}{ Burned area $\left(\mathrm{km}^{2}\right)$} & \multicolumn{2}{|c|}{ Total consumption $(\mathrm{Tg})$} & \multicolumn{2}{|c|}{ Total $\mathrm{CO}_{2}(\mathrm{Tg})$} \\
\hline & CONUS & $\mathrm{AK}$ & CONUS & $\mathrm{AK}$ & CONUS & $\mathrm{AK}$ \\
\hline 2001 & 8182 & 438 & 16.38 & 9.07 & 13.79 & 7.18 \\
\hline 2002 & 13744 & 8518 & 51.98 & 126.09 & 44.19 & 99.91 \\
\hline 2003 & 18450 & 2322 & 55.62 & 24.00 & 50.37 & 19.08 \\
\hline 2004 & 10223 & 26407 & 16.34 & 363.23 & 15.53 & 288.19 \\
\hline 2005 & 17918 & 19507 & 23.17 & 292.00 & 21.24 & 231.38 \\
\hline 2006 & 26903 & 1087 & 59.66 & 9.61 & 51.03 & 7.68 \\
\hline 2007 & 29637 & 2445 & 82.83 & 23.93 & 71.86 & 19.03 \\
\hline 2008 & 17524 & 402 & 50.38 & 5.19 & 42.45 & 4.11 \\
\hline 2009 & 15944 & 11359 & 24.25 & 163.11 & 22.22 & 129.37 \\
\hline 2010 & 12414 & 4313 & 14.93 & 48.43 & 12.09 & 38.50 \\
\hline
\end{tabular}

of total emissions, with 2007 being the highest year for burned area and $\mathrm{CO}_{2}$ emissions for CONUS or 2004 for AK (Table 4).

The percentage of fuel consumption (also known as combustion completeness) for CONUS, AK, and each ecoregion was computed in WFEIS for 2000-10 using the MODIS MCD64A1 burned area product (Figure 4). The mean, median, and standard deviation of annual consumption in all fires were derived from the set of up to 11 years of estimated percentage of total fuel loading consumed. Also shown is the mean fuel consumption across all years. This measure is often used in broadscale modeling of fire emissions and can reveal geographic patterns of fire's contribution to carbon emissions (Hayes et al. 2011).

Comparisons were made with published emissions estimates from GFEDv3 (van der Werf et al. 2010) for CONUS [temperate North America (TENA) in the GFEDv3 assessment]. When evaluating GFEDv3 against WFEIS using the MODIS MCD64a1 burned area product-which is the same base burned area data used in the GFEDv3 and GFEDv4 estimates for post-2000-results are comparable, with WFEIS being higher in some years than GFEDv3 and lower in others (Figure 5).

\section{Discussion}

Calculation of retrospective emissions from wildland fire has been accomplished using similar approaches with several model systems (French et al. 2011; Larkin et al. 2009; Urbanski et al. 2011; Wiedinmyer et al. 2011). For example, GFEDv3 produces coarse-resolution (at $0.5^{\circ}$ of latitude) global products of emissions that are precomputed and served out as monthly spatial estimates; the next version will be at a finer grid scale. Emissions are computed from satellite-driven model estimates of biomass, predefined values for fuel consumption that vary with fuel type and time, and other global-scale input datasets. The FINN model also provides global emissions data (Wiedinmyer et al. 2011), at a much finer resolution than GFEDv3, but the results do not include estimates of total carbon emissions and the method does not employ detailed fuel and fuel consumption information. WFEIS is used to calculate emissions at user-specified locations at a moderate spatial scale (1-km cell size), employing field-derived data on fuels and fuel moisture, providing 

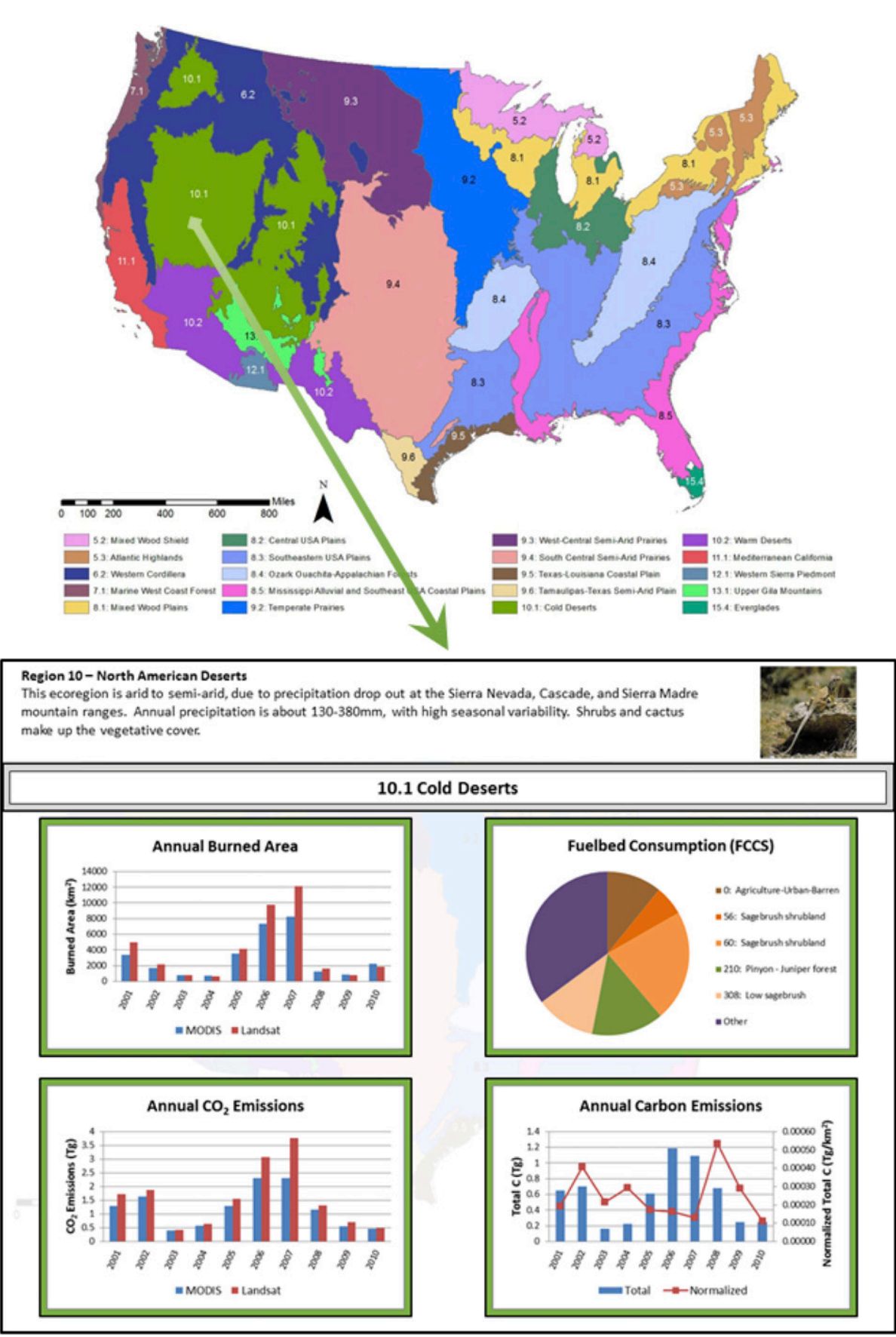

Figure 3. Example of results from WFEIS v0.3 for ER 10.1. The same results for each CONUS ecoregion are available through an interactive map (see supplemental file online at http://dx.doi.org/10.1175/EI-D-14-0002.s1). Click on any level-2 ecoregion on the map to display a general description of the level- 1 ecoregion and graphs of the proportion of dominant fuel beds in the ecoregion, annual area burned, annual $\mathrm{CO}_{2}$ emissions, and annual carbon emissions for the ecoregion for 2001-10 (also available at http:// wfeis.mtri.org/ecoregion_summaries). 
Earth Interactions - Volume 18 (2014) • Paper No. 16 • Page 17

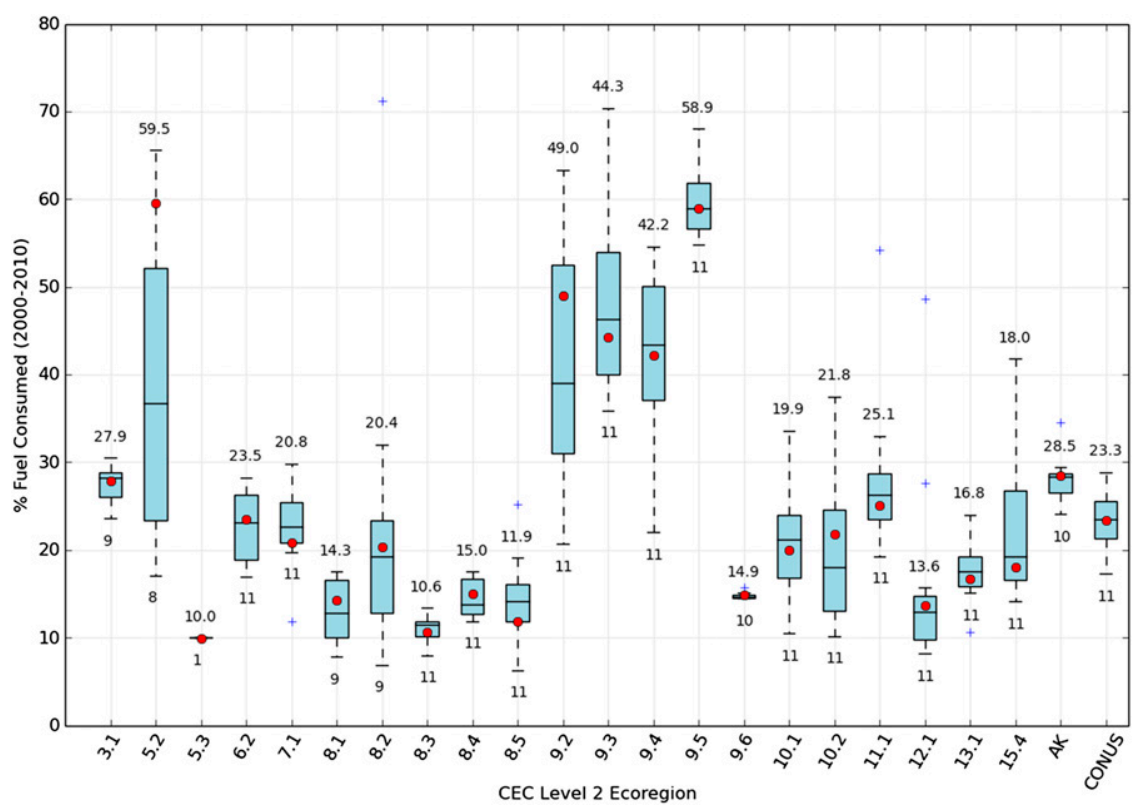

Figure 4. Percentage fuel consumption computed in WFEIS v0.3 for CONUS, AK, and each ecoregion within the United States (see Figure 3 for a map of ecoregions by number) based on fires from 2000 through 2010 within burned areas in the MODIS MCD64A1 burned area product. The value to the bottom of each box plot represents the number of years with fire, so in ecoregions where $n<11$ the ecoregion had years with no detected fire. Red dots and the values on top of each box plot represent mean percentage fuel consumption for all fires over the entire time period for each ecoregion, while box plots show the interannual variability. Results for agricultural-dominated ecoregions (8.1, 8.2, 8.5, and 9.2) are based on limited data that may not fully represent the ecoregion because of a lack of fuel data in croplands in version 0.3 of WFEIS; fire was detected in just one year in ecoregion 5.3, so values for these regions should be used with caution and may not be reliable estimates.

variability in consumption that is closer to what is measured on the ground than with these global approaches. The WFEI (Urbanski et al. 2011) and the BlueSky modeling framework (Larkin et al. 2009) are similar to WFEIS; they employ fieldderived fuels information and use input data and models similar to WFEIS. The WFEI provides only $\mathrm{CO}$ and particulate emissions estimates but also provides a detailed accounting of uncertainty, which has great value for improving emissions estimation methods and results. BlueSky provides access to smoke information for smoke and air quality management of wildfire and prescribed burning. It also provides a structure to link a variety of independent models of fire information, fuel loading, fire consumption, fire emissions, and smoke dispersion to assess fire impacts on air quality and visibility. Standard outputs for smoke management are available from the BlueSky system and includes the BlueSky Playground (http:// www.airfire.org/data/playground/), a user-friendly tool that integrates location 


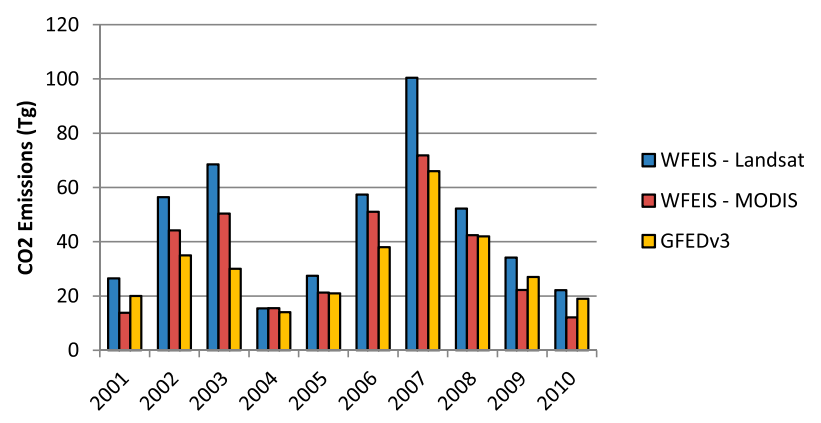

Figure 5. Comparison of $\mathrm{CO}_{2}$ emissions computed within WFEIS using MODIS MCD64A1 and the Landsat MTBS burn area products to results from the GFEDv3 database (van der Werf et al. 2010).

information with fuels to allow users to assess the smoke emissions from actual or hypothetical fires. Its functionality is similar to WFEIS, but it includes smoke dispersion modeling. Unlike WFEIS, the BlueSky Playground is limited to pointbased assessments rather than spatially explicit estimates across a burned area. WFEIS provides a very similar set of tools as BlueSky, minus the atmospheric transport, but through a different type of web interface and software structure that allows flexibility in user access and future system development because of the open-source software architecture. Also on the horizon is a spatial version of the First Order Fire Effects Model (FOFEM; Reinhardt et al. 1997; http://www.fs.fed. us/fmi/projects/abstracts/Helmbrecht_SpatialFOFEM_abstract.html). FOFEM computes several fire effects attributes in addition to fire emissions, but the spatial version will operate within ArcGIS, so it will not have the full flexibility for development provided by the open-source architecture of WFEIS.

A previously reported comparison of results from WFEIS with other emissions estimation methods (French et al. 2011) showed that WFEIS often estimates higher levels of consumption and emissions of $\mathrm{CO}_{2}$ and other greenhouse gases than other models, including GFEDv3. Because the "true" emissions levels are unknown, it cannot be known which method(s) is more accurate. More testing and attention to quantifying uncertainty in all methods needs to be done. It is possible that WFEIS produces higher estimates than other methods because Consume and the fuel represented in the FCCS accounts for all biomass that has the potential to burn, whereas other approaches exclude some fuel-bed components. An assessment of canopy loadings using MODIS data shows that FCCS default canopy loadings are higher on average than satellite-derived estimates, meaning the WFEIS estimates may be biased higher because of higher canopy fuel loadings. However, excluding canopy consumption, as some estimation methods do, is not necessarily any more accurate; there are not enough data on canopy consumption to produce a best estimate. Similarly, shrub consumption within WFEIS, which is based on assuming $50 \%$ of the site is blackened by fire, is imprecise because of the lack of a more rigorous method to account for consumption of shrub biomass. Many of the assumptions in the current implementation of Consume have not been tested, so their influence is not fully understood. 
Earth Interactions - Volume 18 (2014) • Paper No. 16 • Page 19

Another feature of WFEIS that can influence emissions and produce higher than other estimates is that Consume provides a detailed accounting of consumption by fuel strata based on mapped fuel type and including flaming versus smoldering combustion. Other approaches use general consumption levels by biome, by vegetation type, or based on simple biophysical conditions. Other approaches also do not explicitly model smoldering combustion. In previous assessments, such as French et al. (2000) and Schultz et al. (2008), consumption is assigned a single value by broad ecoregion (e.g., Alaska boreal interior, which covers entire boreal forest region of Alaska) or general ecosystem type (e.g., forest versus woodland versus grassland) with no accounting for spatial variability, vegetation strata, or combustion type. This is a broad assumption when fuel type and condition are known to vary significantly across geographic regions and between ecosystem types. The GFED approach, conversely, assigns consumption based on vegetation type, and consumption is applied by vertical fuel strata similar to WFEIS. Since none of the models compared in the French et al. (2011) analysis included an accuracy assessment, it is difficult to know if the generally higher results with WFEIS are a systematic bias because of these assumptions or are derived from some other source. The consequences of overestimating emissions (or underestimating emissions) are related to accurate assessments of the influence of fire on air quality and the role of fire in carbon cycling. Actions to control or mitigate for fire emissions for health or climate considerations may be made based on estimations such as those provided with WFEIS. Improving our understanding of the uncertainty of these types of estimates is an important next step.

The emissions results served out by WFEIS have value for a wide set of users. Currently, users can perform multiple runs to compare, for example, emissions from one region to another or across one region over time (e.g., monthly, annually, or decadally; see Tables 3 and 4 and Figure 3). Examining the variability of emissions from one region to another, it becomes apparent that burned area is not the only driver of the magnitude of emissions. Ecoregions with low overall biomass have lower fuel consumption and emissions (e.g., North American deserts) than areas where large and complex forest types dominate the landscape and fire is more prevalent (e.g., northwestern forested mountains; Table 3 and Figure 3). Year-toyear or season-to-season variability in the amount of area burned and the resulting emissions are also apparent when looking across annual data results (Table 4). The types of summary outputs presented in Figure 3 and Tables 3 and 4 can be valuable for understanding patterns of emissions from fire across large spatial and temporal scales or across seasons.

The proportion of fuel consumed by biome or ecoregion is commonly used in modeling at regional and global scales (e.g., French et al. 2000; Hayes et al. 2011; Hoelzemann et al. 2004; Seiler and Crutzen 1980; van der Werf et al. 2010). With WFEIS, we are able to summarize consumption using the total fuel loads of the sites burned and the amount of fuel consumed (Table 4 and Figure 4). This information shows that consumption varies between ecoregions, mainly because of fuels and fuel moisture variability, and from one year to the next, driven primarily by fuel moisture conditions. It should be noted that for some ecoregions the WFEIS data do not properly represent the proportion of fuel consumed because of the lack of available data and the modeling assumptions. In particular, ecoregions (ER) with high percentage consumed (ER 9.5 with $59 \%$ and ER 11.1 with 26\%) are 
Earth Interactions - Volume 18 (2014) • Paper No. 16 • Page 20

dominated by shrublands. Shrub consumption in WFEIS is assumed to be $50 \%$, which may be inappropriate in some regions, although this is not well known. Similarly, the mixed-wood shield (ER 5.2) shows a large variability in percentage consumed likely due to the variability in fuel types that burn, and the Atlantic highlands (ER 5.3) had just one year with fire in CONUS, which may not properly represent all fire in the region. Estimates from prairie and some plains ecoregions (ERs 8.2, 8.5, and 9.2-9.6) may be poorly constrained because many fires in these ecoregions occur in cropland types. Cropland emissions are not accounted for because cropland fuels have not been mapped for WFEIS so fuels loadings are set to zero in this land-cover type. Consequently, emissions in cropland-dominated ecoregions are underestimated if agricultural burning is substantial.

In some cases, the proportion of fuel consumed computed from WFEIS (Figure 4 ) is within range of previously reported values. For example, Alaska boreal interior (ER 3.1) is $28.3 \%$ from this WFEIS assessment. GFEDv3 results (van der Werf et al. 2010) report $23 \%$ and $69 \%$ for aboveground and surface consumption in the boreal region, respectively; French et al. (2000) use $23 \%$ for aboveground and $36 \%$ for surface fuels for ecoregion 3.1 and $25 \%$ for aboveground in most of the remainder of the North American boreal regions. The GFEDv3 results for temperate North America, which primarily covers CONUS, are 17\% and $75 \%$ for aboveground and surface consumption, respectively, while WFEIS consumption values vary by ecoregion and range from $12.8 \%$ in ER 8.1 mixed-wood plains to $36.7 \%$ in ER 5.2 mixed-wood shield. These studies, therefore, generally agree for the aboveground portion of fuels. However, several global emissions assessments from the atmospheric science community (Hoelzemann et al. 2004; Reid et al. 2005) use consumption percentages of $85 \%$ for grassland savannas, $60 \%$ for woodland savannas, and $50 \%$ for forestlands. While these values are broad assumptions, they follow a logical pattern of higher proportion of fuel consumed in grasslands and shrublands and lower proportion consumed in forest fuels types. However, as reviewed here, many previous studies and the work with WFEIS indicate that consumption in forested fuel types is well below 50\%, except in types that have deep organic soils that are known to be consumed in wildfire.

\section{Improvements, enhancements, and future application of WFEIS}

As WFEIS is improved, a major focus will be on system evaluation and testing to assess the validity and utility of the system outputs. Currently, we are finding loweffort ways to improve datasets and the modeling system, including importing additional years of burn area data and investigating possible improvements to the emission factors, since there are new published data available. Improvements by the USFS to Consume are being integrated as available, and we have an effort underway to determine ways to assess the uncertainty in the model outputs. This work will help guide the development of WFEIS along with several desired enhancement tasks.

One planned enhancement will be to integrate better information on burned area. The maps from Landsat and MODIS currently available within WFEIS are known to have discrepancies when compared with fire records. An example is the 


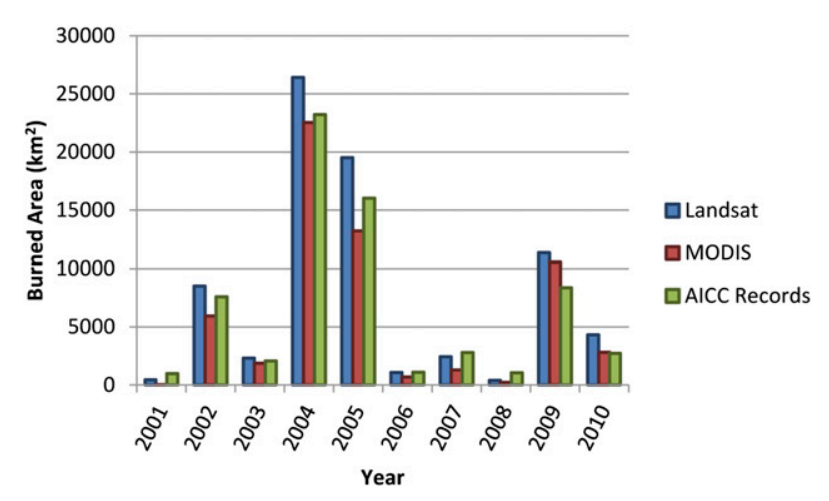

Figure 6. Comparison of burned area in AK for 2001-10 from products used in WFEIS (Landsat MTBS and MODIS MCD64A1) and the Alaska Interagency Coordination Center (AICC) fire records (http://fire.ak.blm.gov/incinfo/ aklgfire.php).

comparison of burn area data from AK for 2001-10. Fire records show that the data in WFEIS from Landsat and MODIS are different from known burned area maps (Figure 6). Since WFEIS is built to be flexible, integration of alternative or additional burned area products is possible and can be incorporated as required. In particular, burning in croplands of CONUS is not well represented within WFEIS. Next steps will include integration of burned area maps specifically developed to detect fires in croplands. The cropland data integration will also include annual cropland type maps with fuel loadings generated from work developed by McCarty (2011) and used by the USEPA for the National Emissions Inventory (http://www. epa.gov/ttnchie1/net/2011inventory.html). The fuel maps will be integrated into WFEIS so that areas currently with zero fuel loading values will instead have realistic emissions when fire is present.

A second proposed improvement in WFEIS is improved representation of canopy fuels in the existing 1-km FCCS map. The MODIS vegetation continuous fields (VCF) data product (Hansen et al. 2003), which estimates percentage cover of woody and nonwoody vegetation and bare ground across North America, has been used to provide spatially explicit and improved estimates of cover in dominant layers (tree canopy for forested fuel beds and shrub cover for shrub fuel beds). From these cover estimates, explicit for each 1-km cell in the data layer, refined fuel loadings for the dominant cover types were calculated, providing much more detailed accounting of the spatial variability in fuel loadings across the domains. This product will be integrated into WFEIS in the next version (version 0.4).

A third data enhancement that is nearly complete is revision of the fuel moisture maps for 1000-h FM and duff FM. The current ecoregion-level products will be replaced with daily gridded data using either RAWS or NARR as the base weather data inputs; various products will be tested to decide the best method. The ecoregion-level products used in version 0.3 were developed to help with computation intensity; the system has since been optimized so that temporally and spatially corresponding fuel moisture values are assigned to burned area data as it is updated, easing concerns about the computational intensity of using higher-resolution 
Earth Interactions - Volume 18 (2014) • Paper No. 16 • Page 22

fuel moisture data. Testing with the new enhanced datasets is ongoing to make sure performance speed is not compromised.

It is expected that WFEIS will continue to be developed to meet a variety of enduser needs. One example of a feasible extension to WFEIS would be to allow users to define or upload regions of interest (e.g., polygons) so that emissions can be estimated for a specific geographic region or hypothetical burned area. The ability to modify fuel-bed inputs over time and at potentially yearly intervals is another modification that would assist in determining the effects of reburn and fire return interval. Another potential feature would be to allow users to run emissions scenarios for hypothetical fires in user-specified locations: emissions scenarios that could be valuable for understanding how fire might impact sensitive regions.

The current version of WFEIS provides a demonstration of the utility of the system for emissions modeling in CONUS and AK. WFEIS has potential to be ported to other places around the world to provide emissions estimation capability at moderate spatial scales, which has value for country-scale emissions inventories and regional-scale air quality assessment.

\section{Summary and conclusions}

WFEIS is a system that provides for the geospatial assessment of emissions from past fires within the United States; it allows users to define a location and time frame of interest within a web-accessible system producing user-friendly spatial or tabular output files. It is unlike other fire emissions models and systems in that it offers a flexible, web-based API. WFEIS uses tools developed for local and landscape-scale fire effects assessment to make emissions estimates at landscape, regional, or continental scales. The FCCS and Consume have been valuable for forest managers and are here being used to assess fuel consumption and emissions across broad spatial scales and serve out results as mapped spatial data. Running WFEIS allows fire researchers, forest and smoke managers, and atmospheric scientists to view how past fires have contributed to emissions that influence air quality and carbon cycling. The magnitude and location of emissions can be assessed and visualized using the output data created within WFEIS.

The architecture of the WFEIS system is novel; open-source geospatial tools allow developers full access and freedom to modify the system and install new features in the future. WFEIS uses a REST software architecture to implement a web-based API, allowing users to store, share, and recall emissions scenarios using short URIs. WFEIS employs innovative web technologies; the web-based emissions calculator provides a browser-independent and user-friendly interface for designing emissions queries. The flexibility of the system architecture and usability of the web interface make WFEIS a valuable tool for making consistent and useful outputs for decision making related to fire emissions.

Acknowledgments. Funding for WFEIS development and the analyses presented here has been supported through grants from the NASA Carbon Cycle Science Program (Grant NNX08AK69G to MTRI and USFS), the NASA Applications Program (Grants NNX09AP53G to the National Institute of Aerospace, A. Soja, PI and NNX12AQ90G to MTRI and USFS), and the NASA Carbon Monitoring Program (Grant NNX12AM91G to MTRI and USFS). The authors acknowledge the help of many research associates, analysts, 
Earth Interactions - Volume 18 (2014) • Paper No. 16 • Page 23

software developers, and interns that were involved in a variety of tasks in the development of WFEIS, especially Eric Keefauver, Jessica McCarty, Kimberly Mobley, Nicholas Molen, Robert Norheim, Reid Sawtell, Kjell Swedin, and Marlene Tyner.

\section{References}

Bailey, R. G., and H. C. Hogg, 1986: A world ecoregions map for resource reporting. Environ. Conserv., 13, 195-202, doi:10.1017/S0376892900036237.

Campbell, J., D. Donato, D. Azuma, and B. Law, 2007: Pyrogenic carbon emission from a large wildfire in Oregon, United States. J. Geophys. Res., 112, G04014, doi:10.1029/2007JG000451.

Cohen, J. D., and J. E. Deeming, 1985: The National Fire-Danger Rating System: Basic equations. Pacific Southwest Forest and Range Experiment Station General Tech. Rep. PSW-82, 16 pp.

Commission for Environmental Cooperation, 1997: Ecological regions of North America: Towards a common perspective. Commission for Environmental Cooperation Rep., 60 pp.

Crutzen, P. J., and M. O. Andreae, 1990: Biomass burning in the tropics: Impact on atmospheric chemistry and biogeochemical cycles. Science, 250, 1669-1678, doi:10.1126/ science.250.4988.1669.

de Groot, W. J., J. Pritchard, and T. J. Lynham, 2009: Forest floor fuel consumption and carbon emissions in Canadian boreal forest fires. Can. J. For. Res., 39, 367-382, doi:10.1139/X08-192.

Deeming, J. E., R. E. Burgan, and J. D. Cohen, 1978: The National Fire-Danger Rating System1978. USDA Forest Service General Tech. Rep. INT-39, 63 pp.

Eidenshink, J., B. Schwind, K. Brewer, Z.-L. Zhu, B. Quayle, and S. Howard, 2007: A project for monitoring trends in burn severity. Fire Ecol., 3, 3-21, doi:10.4996/fireecology.0301003.

French, N. H. F., E. S. Kasischke, B. J. Stocks, J. P. Mudd, D. L. Martell, and B. S. Lee, 2000: Carbon release from fires in the North American boreal forest. Fire, Climate Change, and Carbon Cycling in the Boreal Forest, E. S. Kasischke, and B. J. Stocks, Eds., Springer-Verlag, 377-388.

$\longrightarrow,-$, R. J. Hall, K. A. Murphy, D. L. Verbyla, E. E. Hoy, and J. L. Allen, 2008: Using Landsat data to assess fire and burn severity in the North American boreal forest region: An overview and summary of results. Int. J. Wildland Fire, 17, 443-462, doi:10.1071/WF08007.

— , and Coauthors, 2011: Model comparisons for estimating carbon emissions from North American wildland fire. J. Geophys. Res., 116, G00K05, doi:10.1029/2010JG001469.

— D. McKenzie, R. D. Ottmar, J. L. McCarty, R. A. Norheim, N. Hamermesh, and A. J. Soja, 2014: A US national fuels database and map for calculating carbon emissions from wildland and prescribed fire. Proc. Fourth Fire Behavior and Fuels Conf., St. Petersburg, Russia, International Association of Wildland Fire, 522-529.

Friedl, M. A., and Coauthors, 2002: Global land cover mapping from MODIS: Algorithms and early results. Remote Sens. Environ., 83, 287-302, doi:10.1016/S0034-4257(02)00078-0.

Giglio, L., J. D. Kendall, and R. Mack, 2003: A multi-year active fire dataset for the tropics derived from the TRMM VIRS. Int. J. Remote Sens., 24, 4505-4525, doi:10.1080/ 0143116031000070283.

— I. Isiszar, and C. O. Justice, 2006: Global distribution and seasonality of active fires as observed with the Terra and Aqua Moderate Resolution Imaging Spectroradiometer (MODIS) sensors. J. Geophys. Res., 111, G02016, doi:10.1029/2005JG000142.

— , T. Loboda, D. P. Roy, B. Quayle, and C. O. Justice, 2009: An active-fire based burned area mapping algorithm for the MODIS sensor. Remote Sens. Environ., 113, 408-420, doi:10.1016/j.rse.2008.10.006.

—, J. T. Randerson, G. R. van der Werf, P. S. Kasibhatla, G. J. Collatz, D. C. Morton, and R. S. DeFries, 2010: Assessing variablity and long-term trends in burned area by merging multiple satellite fire products. Biogeosciences, 7, 1171-1186, doi:10.5194/bg-7-1171-2010.

Goovaerts, P., 1997: Geostatistics for Natural Resources Evaluation. Oxford University Press, $483 \mathrm{pp}$. 
Earth Interactions - Volume 18 (2014) • Paper No. 16 • Page 24

Guild, L. S., J. B. Kauffman, L. J. Ellingson, D. L. Cummings, E. A. Castro, R. Babbitt, and D. Ward, 1998: Dynamics associated with total aboveground biomass, C, nutrient pools, and biomass burning of primary forest and pasture in Rondonia, Brazil during SCAR-B. J. Geophys. Res., 103, 32 091-32 100, doi:10.1029/98JD00523.

Hansen, M., R. S. DeFries, J. G. R. Townshend, M. Carroll, C. DiMiceli, and R. A. Sohlberg, 2003: Global percent tree cover at a spatial resolution of 500 meters: First results of the MODIS vegetation continuous fields algorithm. Earth Interact., 7, doi:10.1175/1087-3562(2003)007<0001: GPTCAA $>2.0 . \mathrm{CO} ; 2$.

Hao, W. M., and M. H. Liu, 1994: Spatial and temporal distribution of tropical biomass burning. Global Biogeochem. Cycles, 8, 495-503, doi:10.1029/94GB02086.

Hawbaker, T. J., V. C. Radeloff, A. D. Syphard, Z. L. Zhu, and S. I. Stewart, 2008: Detection rates of the MODIS active fire product in the United States. Remote Sens. Environ., 112, 2656-2664, doi:10.1016/j.rse.2007.12.008.

Hayes, D. J., A. D. McGuire, D. W. Kicklighter, K. R. Gurney, T. J. Burnside, and J. M. Melillo, 2011: Is the northern high-latitude land-based $\mathrm{CO}_{2}$ sink weakening? Global Biogeochem. Cycles, 25, GB3018, doi:10.1029/2010GB003813.

Hoelzemann, J. J., M. G. Schultz, G. P. Brasseur, C. Granier, and M. Simon, 2004: Global Wildland Fire Emission Model (GWEM): Evaluating the use of global area burnt satellite data. J. Geophys. Res., 109, D14S04, doi:10.1029/2003JD003666.

Hyer, E. J., and J. S. Reid, 2009: Baseline uncertainties in biomass burning emission models resulting from spatial error in satellite active fire location data. Geophys. Res. Lett., 36, L05802, doi:10.1029/2008GL036767.

Joint Fire Science Program, 2009: Consume 3.0-A software tool for computing fuel consumption. Joint Fire Science Program Fire Science Brief 55, 6 pp.

Kasischke, E. S., and J. E. Penner, 2004: Improving global estimates of atmospheric emissions from biomass burning. J. Geophys. Res., 109, D14S01, doi:10.1029/2004JD004972.

— , T. Loboda, L. Giglio, N. H. F. French, E. E. Hoy, B. de Jong, and D. Riaño, 2011: Quantifying burned area from fires in North American forests: Implications for direct reduction of carbon stocks. J. Geophys. Res., 116, G04003, doi:10.1029/2011JG001707.

Key, C. H., and N. C. Benson, 2005: Landscape assessment: Ground measure of severity, the composite burn index, and remote sensing of severity, the normalized burn index. FIREMON: Fire Effects Monitoring and Inventory System, D. C. Lutes, Ed., USDA Forest Service General Tech. Rep. RMRS-GTR-164-CD, 16 pp.

Larkin, N. K., and Coauthors, 2009: The BlueSky smoke modeling framework. Int. J. Wildland Fire, 18, 906-920, doi:10.1071/WF07086.

Law, B. E., D. Turner, J. Campbell, O. J. Sun, S. Van Tuyl, W. D. Ritts, and W. B. Cohen, 2004: Disturbance and climate effects on carbon stocks and fluxes across western Oregon USA. Global Change Biol., 10, 1429-1444, doi:10.1111/j.1365-2486.2004.00822.x.

Lawson, B. D., G. N. Dalrymple, and B. C. Hawkes, 1997: Predicting forest floor moisture contents from duff moisture code values. Forestry Research Applications Pacific Forestry Centre Technology Transfer Note 6, 4 pp.

Le Page, Y., J. M. C. Pereira, R. Trigo, C. da Camara, D. Oom, and B. Mota, 2008: Global fire activity patterns (1996-2006) and climatic influence: An analysis using the World Fire Atlas. Atmos. Chem. Phys., 8, 1911-1924, doi:10.5194/acp-8-1911-2008.

Loboda, T., and I. Csiszar, 2007: Reconstruction of fire spread within wildland fire events in northern Eurasia from the MODIS active fire product. Global Planet. Change, 56, 258-273, doi:10.1016/j.gloplacha.2006.07.015.

Mayaux, P., and Coauthors, 2006: Validation of the global land cover 2000 map. IEEE Trans. Geosci. Remote Sens., 44, 1728-1739, doi:10.1109/TGRS.2006.864370.

McCarty, J. L., 2011: Remote sensing-based estimates of annual and seasonal emissions from crop residue burning in the contiguous United States. J. Air Waste Manage. Assoc., 61, 22-34, doi:10.3155/1047-3289.61.1.22. 
Earth Interactions - Volume 18 (2014) • Paper No. 16 • Page 25

— C. O. Justice, and S. Korontzi, 2007: Agricultural burning in the southeastern United States detected by MODIS. Remote Sens. Environ., 108, 151-162, doi:10.1016/j.rse.2006.03.020.

McKenzie, D., N. H. F. French, and R. D. Ottmar, 2012: National database for calculating fuel available to wildfires. EOS, Trans. Amer. Geophys. Union, 93, 57-58, doi:10.1029/2012EO060002.

Michalek, J. L., N. H. F. French, E. S. Kasischke, R. D. Johnson, and J. E. Colwell, 2000: Using Landsat TM data to estimate carbon release from burned biomass in an Alaskan spruce complex. Int. J. Remote Sens., 21, 323-338, doi:10.1080/014311600210858.

Ottmar, R. D., 2014: Wildland fire emissions, carbon, and climate: Modeling fuel consumption. For. Ecol. Manage., 317, 41-50, doi:10.1016/j.foreco.2013.06.010.

— Washington and western Oregon. USDA Forest Service Research Paper PNW-336, 20 pp.

,-- C. L. Riccardi, and S. J. Prichard, 2007: An overview of the Fuel Characteristic Classification System (FCCS)—Quantifying, classifying, and creating fuelbeds for resource planning. Can. J. For. Res., 37, 2383-2393, doi:10.1139/X07-077.

— A. Miranda, and D. Sandberg, 2009: Characterizing sources of emissions from wildland fires. Wildland Fires and Air Pollution, A. Bytnerowicz et al., Eds., Elsevier, 61-78.

Pouliot, G., T. G. Pace, B. Roy, T. Pierce, and D. Mobley, 2008: Development of a biomass burning emissions inventory by combining satellite and ground-based information. J. Appl. Remote Sens., 2, 021501, doi:10.1117/1.2939551.

Prichard, S. J., R. D. Ottmar, and G. A. Anderson, 2009: Consume 3.0 user's guide. USDA Forest Service Pacific Wildland Fire Sciences Laboratory Rep., 239 pp. [Available online at http:// www.fs.fed.us/pnw/fera/research/smoke/consume/consume30_users_guide.pdf.]

— , D. V. Sandberg, R. D. Ottmar, E. Eberhardt, A. Andreu, P. Eagle, and K. Swedin, 2013: Fuel Characteristic Classification System version 3.0: Technical documentation. USDA Forest Service General Tech. Rep. PNW-GTR-887, 79 pp.

Raffuse, S. M., N. K. Larkin, P. W. Lahm, and Y. Du, 2012: Development of version 2 of the wildland fire portion of the National Emissions Inventory. 20th Int. Emissions Inventory Conf., Tampa, FL, Environmental Protection Agency, 12 pp.

Reid, J. S., R. Koppmann, T. F. Eck, and D. P. Eleuterio, 2005: A review of biomass burning emissions part II: Intensive physical properties of biomass burning particles. Atmos. Chem. Phys., 5, 799-825, doi:10.5194/acp-5-799-2005.

Reinhardt, E. D., R. E. Keane, and J. K. Brown, 1997: First Order Fire Effects Model: FOFEM 4.0, user's guide. USDA Forest Service General Tech. Rep. INT- GTR-344, 72 pp.

Riccardi, C. L., R. D. Ottmar, D. V. Sandberg, A. Andreu, E. Elman, K. Kopper, and J. Long, 2007a: The fuelbed: A key element of the Fuel Characteristic Classification System. Can. J. For. Res., 37, 2394-2412, doi:10.1139/X07-143.

— S. J. Prichard, D. V. Sandberg, and R. D. Ottmar, 2007b: Quantifying physical characteristics of wildland fuels using the Fuel Characteristic Classification System. Can. J. For. Res., 37, 2413-2420, doi:10.1139/X07-175.

Roy, D. P., L. Boschetti, C. O. Justice, and J. Ju, 2008: The collection 5 MODIS burned area product-Global evaluation by comparison with the MODIS active fire product. Remote Sens. Environ., 112, 3690-3707, doi:10.1016/j.rse.2008.05.013.

Scepan, J., 1999: Thematic validation of high-resolution global land-cover data sets. Photogramm. Eng. Remote Sens., 65, 1051-1060.

Schultz, M. G., 2002: On the use of ATSR fire count data to estimate the seasonal and interannual variability of vegetation fire emissions. Atmos. Chem. Phys., 2, 387-395, doi:10.5194/ acp-2-387-2002.

— Cycles, 22, GB2002, doi:10.1029/2007GB003031.

Seiler, W., and P. J. Crutzen, 1980: Estimates of gross and net fluxes of carbon between the biosphere and atmosphere from biomass burning. Climatic Change, 2, 207-247, doi:10.1007/ BF00137988. 
Stocks, B. J., and Coauthors, 2002: Large forest fires in Canada, 1959-1997. J. Geophys. Res., 107, 8149, doi:10.1029/2001JD000484.

Tansey, K., J.-M. Grégoire, P. Defourny, R. Leigh, J.-F. Pekel, E. van Bogaert, and E. Bartholomé, 2008: A new, global, multi-annual (2000-2007) burnt area product at $1 \mathrm{~km}$ resolution. Geophys. Res. Lett., 35, L01401, doi:10.1029/2007GL031567.

Urbanski, S. P., W. M. Hao, and B. Nordgren, 2011: The wildland fire emission inventory: Western United States emission estimates and an evaluation of uncertainty. Atmos. Chem. Phys., 11, 12 973-13 000, doi:10.5194/acp-11-12973-2011.

van der Werf, G. R., J. T. Randerson, L. Giglio, G. J. Collatz, P. S. Kasibhatla, and A. F. Arellano Jr, 2006: Interannual variability of global biomass burning emissions from 1997 to 2004. Atmos. Chem. Phys., 6, 3423-3441, doi:10.5194/acp-6-3423-2006.

— , and Coauthors, 2010: Global fire emissions and the contribution of deforestation, savanna, forest, agricultural, and peat fires (1997-2009). Atmos. Chem. Phys., 10, 11707-11735, doi:10.5194/acp-10-11707-2010.

Van Wagner, C. E., 1987: Development and structure of the Canadian Forest Fire Weather Index System. Canadian Forest Service Forestry Tech. Rep. 35, 48 pp.

Wiedinmyer, C., S. K. Akagi, R. J. Yokelson, L. K. Emmons, J. A. Al-Saadi, J. J. Orlando, and A. J. Soja, 2011: The Fire INventory from NCAR (FINN): A high resolution global model to estimate the emissions from open burning. Geosci. Model Dev., 4, 625-641, doi:10.5194/ gmd-4-625-2011.

Earth Interactions is published jointly by the American Meteorological Society, the American Geophysical Union, and the Association of American Geographers. Permission to use figures, tables, and brief excerpts from this journal in scientific and educational works is hereby granted provided that the source is acknowledged. Any use of material in this journal that is determined to be "fair use" under Section 107 or that satisfies the conditions specified in Section 108 of the U.S. Copyright Law (17 USC, as revised by P.IL. 94553) does not require the publishers' permission. For permission for any other from of copying, contact one of the copublishing societies. 